\title{
ESG METRICS IN FIRM RISK ASSESSMENT: EVIDENCE FROM SHORT SELLING
}

\author{
Thomas F. Lewis, Jr., Norfolk State University, Norfolk, Virginia, U.S.A.
}

dx.doi.org/10.18374/JABE-20-3.9

\begin{abstract}
This study investigates the value-relevance of environmental, social and governance (ESG) metrics in the formulation of investment decisions. Specifically, the extent to which investors utilize ESG metrics in executive compensation contracts to formulate risk assessment in investing decisions. Prior research regards short sellers as particularly sophisticated investors with a desire to understand a company's value creation plan by analyzing credible, standardized information to support risk assessment. However, a serious gap exists between corporates and investors over the standardization and consistency of ESG information and reporting. Prior research about the effect of executive compensation on ESG has been limited in scope and produced mixed results. These studies primarily focus on the use of ESG targets in executive compensation contracts as opposed to the effects of said targets on investment decisions. Using a hand-collected data set, the relationships between short interest, financial and ESG measures in executive compensation contracts are examined. The results show a correlation between short positions and the effectiveness of ESG target measures in executive compensation contracts indicating short sellers do incorporate the measures when assessing risk.
\end{abstract}

Keywords: ESG, Executive Compensation, Short sellers, Risk Assessment, Reporting targets 